\title{
DESNUTRIÇÃO NO PACIENTE GASTRECTOMIZADO
}

DESCRITORES - Transtornos nutricionais. Gastrectomia. Síndromes de pós-gastrectomia.

Durante várias gerações a gastrectomia foi a pedra de toque da cirurgia geral e digestiva. Nenhum cirurgião abdominal se considerava apto para as lides diárias se não se desincumbisse a contento de uma, e residentes cirúrgicos freqüentemente cotavam o sucesso ou fracasso do seu estágio pelo número de gastrectomias que haviam executado.

Consta que o famoso Professor Benedito Montenegro, talvez o mais reverenciado criador da escola cirúrgica paulista, foi agraciado muitas décadas atrás com diploma de Campeão da Gastrectomia pelo Colégio Americano de Cirurgiões, mercê de milhares de exéreses parciais e totais daquela víscera que havia perpetrado. Também o Dr. Eurico Branco Ribeiro, patrono de um dos hospitais mais tradicionais de São Paulo, não desdenhava citar as mais de 3000 gastrectomias que contabilizava em seu passado profissional, número aliás que encontra paralelo em outras grandes figuras cirúrgicas do passado.

Eram estas operações apropriadas? À luz dos conhecimentos atuais, e sobretudo das alternativas farmacológicas e mesmo cirúrgicas mais conservadoras de que se dispõe, a resposta para a vasta maioria dos casos benignos seria não. Somente no câncer avançado e diante de complicações graves e rebeldes da enfermidade ulcerosa ao lado de outras situações selecionadas, cabe na modernidade a ablação parcial ou total do reservatório gástrico ${ }^{(2)}$.

Há uma ou duas gerações o raciocínio era distinto e a gastrectomia parcial não era claramente percebida como intervenção mutilante. Ao contrário, diante dos padecimentos da moléstia péptica, da fraca eficácia dos antiácidos clássicos, da angústia das dietas lácteas, brandas e insossas, e da tortura de nunca poder degustar sem remorsos um café ou uma bebida alcoólica, os enfermos se submetiam de bom grado ao bisturi do cirurgião ${ }^{(4)}$.

Evidentemente os malefícios metabólicos da perda do reservatório gástrico não são propriamente novidade, havendo ciência do déficit de fator intrínseco e do potencial digestivo cloridropéptico, da destruição dos mecanismos regulatórios pilóricos, da dessincronização dos estímulos mecânicos, químicos e hormonais gastrointestinais na reconstrução tipo BII, e dos incômodos possíveis do refluxo, dumping e/ou diarréia. Ainda assim, tais danos eram creditados quase unicamente às ressecções totais, particularmente no contexto do câncer ${ }^{(6)}$.

O desastre nutricional tardio mais temido da gastrectomia parcial era, na realidade, infreqüente e se prendia a uma reconstrução falha, nominalmente a gastroileostomia inadvertida. Nesta última eventualidade, o paciente retornava com tamanho emagrecimento, que formas atenuadas da intervenção serviram de inspiração para algumas modalidades atuais de cirurgia antiobesidade, ditas disabsortivas ${ }^{(1)}$.

Efetivamente as operações bariátricas exclusivamente restritivas ou mistas são também filhas da gastrectomia de outrora, sendo que os cirurgiões aprenderam ao longo dos últimos 120 anos, que a supressão parcial da bolsa gástrica, dependendo de alguns detalhes técnicos, já é capaz de interferir bastante com o padrão alimentar e a composição corpórea dos pacientes ${ }^{(5)}$.

Evidentemente a experiência internacional não desmentiu que a gastrectomia total merece toda a angústia com os resultados nutricionais tardios que tradicionalmente a cerca, porém reforçou o papel também da retirada parcial em desfechos ocasionalmente preocupantes. Perda de peso, anemia, descalcificação óssea, alterações menstruais, dumping, malestar geral e, em conjunturas mais extremas, hipoalbuminemia e edema carencial, estão todos já demonstrados neste contexto. A propósito, o artigo deste número dos ARQUIVOS de GASTROENTEROLOGIA de autoria de PAPINI-BERTO et al. ${ }^{(3)}$, contribui com material valioso e bem documentado a respeito de vários destes aspectos.

Para onde se dirige a prática clínica no presente momento? Por sorte não somente o tratamento das afecções gastroduodenais é hoje mais racional que em outras eras, como o manejo dos quadros disabsortivos porventura deflagrados 
também se efetua com maior eficiência. As ferramentas de avaliação e monitorização nutricional permitem um rastreamento preciso das anomalias em curso e os suplementos comercialmente disponíveis, sejam eles vitamínico-minerais, calórico-protéicos completos ou modulares, ensejam uma compensação nutricional acessível e confiável ${ }^{(2)}$.

Faz sentido tecer-se algumas considerações finais sobre as perspectivas da questão, conforme se segue:

1. A gastrectomia parcial ou total pode se revestir de inconveniente nutricionais insofismáveis, porém não de molde a se renunciar ao seu emprego face a indicações cirúrgicas legítimas, benignas ou malignas;
2. Desde que corretamente realizada e acompanhada, não há razões para se temer as eventuais conseqüências adversas, posto que em mãos experientes, os recursos farmacológicos e dietéticos disponíveis são de regra suficientes para sua reversão.

3. O momento é, pois, de alerta para a comunidade profissional, tal como propiciado pelo artigo do corrente número ${ }^{(3)}$, destacando-se não só a relevância das suspeitas diagnósticas, como a presteza dos posicionamentos terapêuticos, pois disto certamente dependerá muito do bem estar e da qualidade de vida desses gastrectomizados.

Joel FAINTUCH

Faintuch J. Malnutrition in the gastrectomized patient. Arq Gastroenterol 2002;39(1):1-2.

HEADINGS - Nutrition disorders. Gastrectomy. Postgastrectomy syndromes.

\section{REFERÊNCIAS BIBLIOGRÁFICAS}

1. Marceau P, Hould FS, Simard S, Lebel S, Bourque RA, Potvin M, Biron S Biliopancreatic diversion with duodenal switch. World J Surg 1988;22:947-54.

2. Meyer JH. Nutritional outcomes of gastric operation. Gastroenterol Clin North Am 1994;23:227-60.

3. Papini-Berto SJ, Maio R, Módolo AK, Santos MDB, Dichi I, Burini RC. Desnutrição protéico-energética no paciente gastrectomizado. Arq Gastroenterol 2002;38(1):3-10.
4. Rosemberg DM, Chacon JP. Tratamento cirúrgico da úlcera gastroduodenal: resultados comparativos da hemigastrectomia associada à vagotomia com a gastrectomia subtotal. Rev Assoc Med Bras 1963;9:23-6.

5. Smith SC, Goodman GN, Edwards CB. Roux-en-Y gastric bypass. A 7-year retrospective review of 3855 patients. Obes Surg 1995;5:314-8.

6. Tsubaraya A, Noguchi Y, Yoshikawa T, Nomura K, Fukuzawa K, Makino T, Imada $\mathrm{T}$, Matsumoto A. Long-term effect of radical gastrectomy on nutrition and immunity. Surg Today 1993;23:320-4. 